\title{
Trauma services requirements in a district general hospital serving a rural area
}

\author{
S J Kinny, D H A Jones
}

Accident Unit, Gwynedd

Hospital, Bangor,

Gwynedd LL57 2PW

S J Kinny, FRCSED,

orthopaedic registrar

D H A Jones, FRCS,

consultant orthopaedic surgeon

Correspondence to: $\mathrm{Mr}$ Jones.

BrMed f 1990;300:504-8

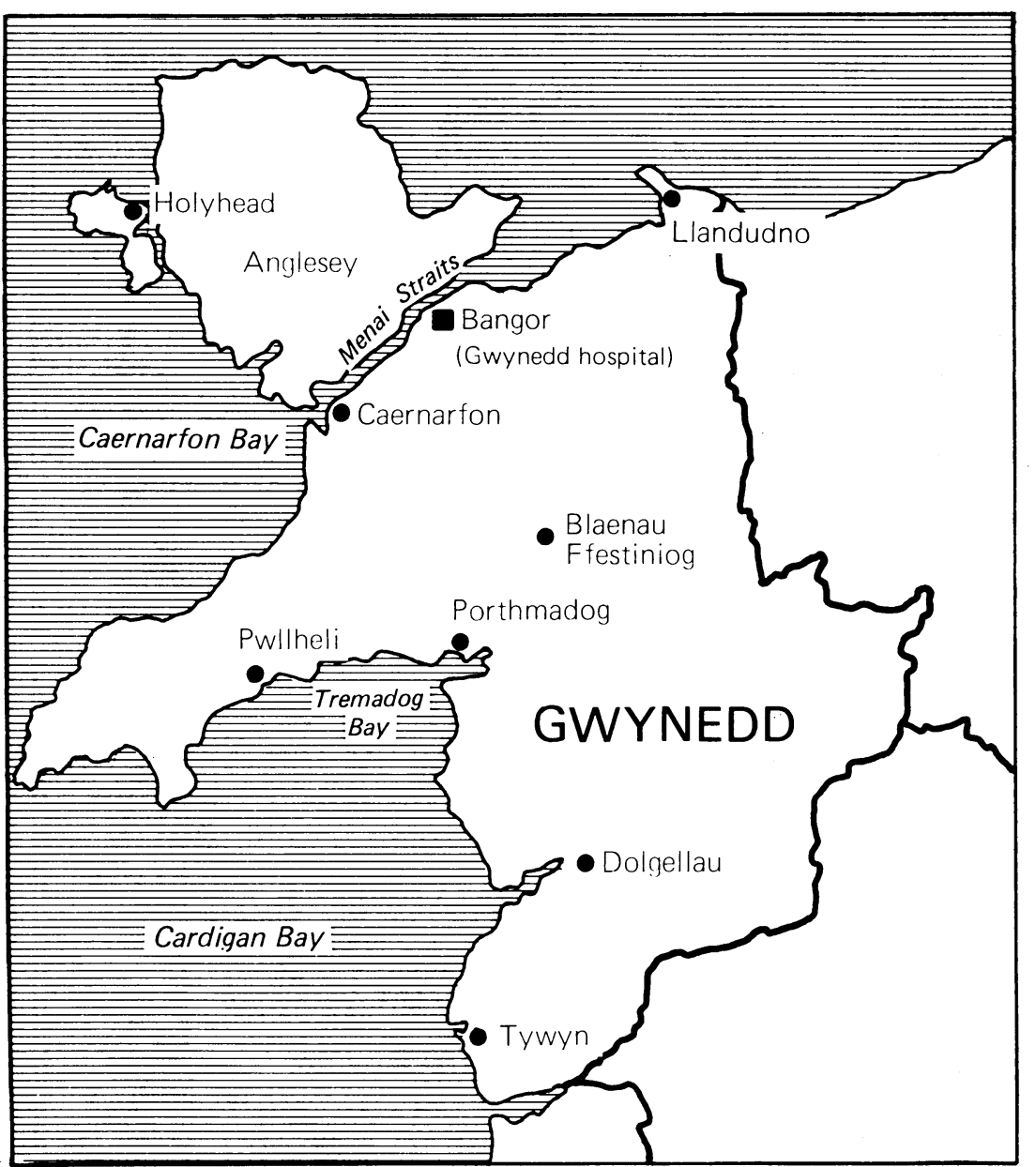

Map of Gwynedd

Main outcome measure-Workload of a district trauma unit.

Results - In August 1988 there were 2325 attendances; 2302 of these were analysed. In all, 1904 attendances were for trauma; 213 patients were admitted to the trauma ward and 103 required an operation that entailed incision. Patients who attended the unit had a mean (range) injury severity score of 2-13 (0-25). Only two patients had injuries that a district general hospital would not be expected to cope with (injury severity score $>20$ ). In the year
Abstract

Objective-To assess the demands made on a regional trauma centre by a district trauma unit.

Design-Two part study. (1) Prospective analysis of one month's workload. (2) Retrospective analysis of one year's workload by using a computer based records system. Comparison of two sets of results.

Setting-Accident unit in Gwynedd Hospital, Bangor.

Patients-(1) All patients who attended the accident unit in August 1988. (2) All patients who attended the accident unit in the calendar year April 1988 - April 1989. district should have only one hospital receiving patients with major trauma. ${ }^{+}$The management of multiple injuries and complex musculoskeletal trauma is generally not possible in small units, and patients should be taken directly to hospitals that have the equipment and staff to deal with them. ${ }^{2+}$ Nondesignated hospitals might incur an increased workload of patients admitted for elective orthopaedic procedures who may be relocated from the district trauma centre.

Set against these arguments for centralising trauma services are factors particularly relevant to rural areas, such as transport difficulties and the traditional bonds and loyalties of patients and staff to local hospitals. ${ }^{5}$ Changes in accident and emergency departments have "knock-on" effects on other departments-for example, reduction or closure of an accident and emergency unit may deprive another specialty of admission facilities for patients with severe problems. The reasons for altering the services must be explained to staff in other departments and the community. Community health councils should be involved early, and they in turn should help educate the public whose welfare is their brief. With regard to the establishment of regional trauma units the British Orthopaedic Association states that it is not possible to assess how pressing the need is for such units until the results of accurate audit are available from district trauma centres.

Gwynedd is a large county comprising Snowdonia, Anglesey, the Lleyn Peninsula, and the coastal strip including the population centres of Bangor, Llandudno, and Caernarfon (figure). The resident population was approaching 240000 in 1988 and is subject to a constant and large seasonal increase caused by holidaymakers.

The major accident centre is in our hospital, which is 
sited well geographically, being in the heart of the county and close to the A55-the North Wales coast road. The accident unit is part of the trauma and orthopaedic service for Gwynedd, which is based at Bangor. The total medical staffing consists of three orthopaedic consultants, an associate specialist, two orthopaedic registrars, and seven senior house officers. All staff work at various times in different parts of the service. At the time of writing the unit comprised an accident and emergency department, a 23 bed severe trauma ward, and two trauma theatres. Accident unit staff deal with all emergencies within their capabilities, but they normally offer continuing care only for those patients with musculoskeletal, head, thermal, chest, and spinal injuries. Patients within the province of other specialties are referred directly to the relevant departments; in cases of multisystem injury the destination of the patient is decided according to clinical priorities. First line cover in the accident unit is provided by one senior house officer in the accident and emergency department (two at busy times) and one in the trauma ward, each working a one in three rota. More senior staff back up the senior house officers, conduct daily trauma operating lists, and undertake fracture and hand clinics in premises adjoining the unit.

There are lesser accident and emergency departments in hospitals at Llandudno, Holyhead, Porthmadog, Pwllheli, and Blaenau Ffestiniog. Patients with serious injuries presenting to these hospitals are referred to our hospital. There are also community hospitals at Dolgellau and Tywyn at the edges of the county, and patients presenting there may be referred to nearer hospitals in adjoining counties. Ambulance staff usually take patients with major trauma directly to our hospital.

We present the workload of our hospital in an attempt to quantify the demands made on it and its regional supporting services.

\section{Methods}

Our study comprised two parts. Firstly, we performed a prospective detailed analysis of all patients who attended the unit in August 1988, a seasonally busy month. Accident and emergency and necropsy records were reviewed by one of us (SJK), and the following were assessed: diagnosis, injury severity score ${ }^{h}$ and outcome. The demands created by these patients on the trauma ward, theatres, and outpatient clinics were also assessed.

Secondly, for the calendar year April 1988 to April 1989 we performed a retrospective analysis of the general workload of the unit by using the computer based accident and emergency records system together with a manual study of the necropsy records for the same period. These figures were correlated with those for August 1988. We also estimated the error factor of such a computer system.

TABLE I-Injury severity scores in patients with trauma who attended in August 1988

\begin{tabular}{cr}
\hline Score & No of patients \\
\hline 0 & 7 \\
1 & 1385 \\
2 & 31 \\
3 & 1 \\
4 & 284 \\
5 & 21 \\
6 & 2 \\
8 & 5 \\
9 & 126 \\
10 & 6 \\
13 & 2 \\
14 & 1 \\
16 & 1 \\
17 & 1 \\
25 & 2
\end{tabular}

\section{Results \\ AUGUST 1988}

In August 1988 there were 2296 patients who created 2325 attendances (there were 29 revisits); 37 patients did not wait to be seen. The accident and emergency records of 13 patients were missing, and two patients could not be classified owing to inadequate information having been recorded. However, the presenting complaint as recorded by the clerical staff at the time of arrival of the patient in the incomplete records and the records of those who did not wait allowed many of these cases to be classified at least as trauma or nontrauma, and in some cases the injury severity score could be calculated.
We analysed 2302 patient attendances. Revisiting patients or any presenting late after trauma (for example, with an infected laceration) were given the same injury severity score as would have applied to the initial injury. We thought that this would most accurately reflect the time demand such patients had made on the unit.

Of the 2302 attendances, $1904(82 \cdot 7 \%)$ were for trauma. Of these, $478(25 \cdot 1 \%)$ were for contusions and abrasions, $413(21.7 \%)$ for fractures or dislocations, $366(19 \cdot 2 \%)$ for lacerations, $242(12 \cdot 7 \%)$ for ligament sprains, and $120(6 \cdot 3 \%)$ for the presence of foreign bodies (including those affecting the eye); all other types of injury each accounted for less than $4 \%$ of attendances. Seventy one patients $(3 \cdot 1 \%)$ had more than one injury.

In all, $213(9 \cdot 2 \%)$ patients were admitted to the trauma ward. Of these, 103 required an operation that entailed incision. The operations included fixation or hemiarthroplasty for fractured neck of the femur $(33$ cases); fixation of ankle fractures (14 cases), and repair of hand injuries (21 cases). Eighty patients required manipulations that did not entail incision and were performed under general, regional, or local anaesthesia, either as overnight or day cases. These included 56 patients with displaced forearm or wrist fractures, seven with displaced midshaft tibial fractures, and eight with dislocated shoulders.

Some patients who required an operation or manipulation were admitted directly to the trauma ward from other hospitals and were included in the operation or manipulation figures. Other admissions to the unit (those not requiring an operation) included mainly elderly patients with minor injuries who were unable to manage on their own and patients with head injuries who were admitted for observation.

Two patients died in the unit, one after failed resuscitation after drowning and another after suffering trauma (an elderly person with a fractured neck of the femur). Two patients required transfer to the regional neurosurgical unit at Liverpool. A patient with a complex acetabular fracture was transferred for consideration of pelvic reconstruction. Only one patient was admitted to general surgery after trauma (the patient had perirenal haematoma). Two patients died outside hospital: one was a pedestrian who had been hit by a car and received instantly fatal head injuries, and the other had a C2/3 fracture dislocation after falling into shallow water.

Those who attended the hospital had a mean (range) injury severity score of $2 \cdot 13(0-25)$ (table I). All patients with an injury severity score $>11$ required admission. All those with a score of $\geqslant 8$ either required admission or had a displaced fracture requiring manipulation under anaesthesia as a day case. All displaced radial fractures such as Colles' fractures scored nine $\left(3^{2}\right)$, as did all fractured necks of the femur. Only two patients had a score of $>20$. The patients who died outside hospital both had a score of 75 .

\section{APRIL 1988-APRIL 1989}

In the calendar year April 1988 to April 1989, 21007 patients attended the unit. Tables II and III show the nature of injury and outcome (by the method of departure) in the patients. Notable features are that $88 \cdot 2 \%$ (17 958) of the attendances were for orthopaedic injuries or those caused by an accident, or both, including deliberate self harm and assault, and $8.6 \%$ (1746) were for medical emergencies; this compares with similar figures of $86 \cdot 2 \%(1980)$ and $9 \cdot 5 \%(218)$, obtained for August. A total of $2175(10.7 \%)$ were referred to one of the outpatient clinics directly, and $1966(9 \cdot 7 \%)$ were admitted to the unit. Most of these patients were also followed up in the outpatient clinics; some, however, were referred back to their own 
regions for follow up or to their general practitioner.

Tables IV and V give a breakdown of the patients' age and type of injury. The annual figures for the four largest age groups are very similar to those obtained above for August alone. About three fifths (10601) of our patients were aged 30 or under, and over three quarters (13658) were aged 45 or under. Table VI shows workload in terms of place of residence. In all, $84.4 \%(17603)$ of the patients were resident in Gwynedd, 15.6\% (3255) coming from elsewhere in the United Kingdom or overseas. In August, proportions

TABLE II -Category of injury or circumstance in patients who attended in April 1988 - April 1989

\begin{tabular}{lrr}
\hline & No & \multicolumn{1}{c}{$\%$} \\
\hline Orthopaedic/caused by accident & 17577 & $86 \cdot 3$ \\
Self harm & 265 & $1 \cdot 3$ \\
Assault & 116 & $0 \cdot 6$ \\
Medical & 1746 & $8 \cdot 6$ \\
Surgical & 346 & $1 \cdot 7$ \\
Psychiatric & 45 & $0 \cdot 2$ \\
No abnormality & 127 & $0 \cdot 6$ \\
Did not wait & 101 & $0 \cdot 5$ \\
Brought in dead & 12 & $0 \cdot 1$ \\
Referred from other hospital & 31 & $0 \cdot 1$ \\
\hline Total by computer & 20366 & 100 \\
Coding error & 641 & \\
Actual total & 21007 &
\end{tabular}

TABLE III-Outcome in patients who attended in April 1988 - April 1989

\begin{tabular}{lrc}
\hline & No & $\%$ \\
\hline Discharged & 10525 & $51 \cdot 7$ \\
Referred to general practitioner & 3436 & $16 \cdot 9$ \\
Advised to revisit & 148 & $0 \cdot 7$ \\
Referred to outpatient department: & & \\
With fracture & 2009 & $9 \cdot 8$ \\
With orthopaedic injury & 33 & $0 \cdot 2$ \\
$\quad$ W'ith hand injury & 143 & $0 \cdot 7$ \\
Admitted to accident unit & 1966 & $9 \cdot 7$ \\
Admitted to other specialties & 1263 & $6 \cdot 2$ \\
Referred to other specialty & 676 & $3 \cdot 3$ \\
Left or refused treatment & 137 & $0 \cdot 7$ \\
Died & 30 & $0 \cdot 1$ \\
\hline Total by computer & 20366 & 100 \\
Coding error & 641 & \\
Actual total & 21007 & \\
\hline
\end{tabular}

TABLE IV-Age of patients with trauma who attended in April $1988-$ April 1989

\begin{tabular}{lrr}
\hline Age (years) & No & $\%$ \\
\hline $0-15$ & 4646 & $26 \cdot 4$ \\
$16-30$ & 5955 & $34 \cdot 1$ \\
$31-45$ & 3057 & $17 \cdot 4$ \\
$46-60$ & 1773 & $10 \cdot 1$ \\
$61-75$ & 1274 & $7 \cdot 3$ \\
$76-90$ & 748 & $4 \cdot 3$ \\
$91-110$ & 68 & $0 \cdot 4$ \\
\hline Total by computer & 17521 & 100 \\
Coding error & 3486 & \\
Actual total & 21007 & \\
\end{tabular}

TABLE $\mathrm{v}-$ Types of injury in patients with trauma who attended in April 1988 - April 1989

\begin{tabular}{lcc}
\hline & No & $\%$ \\
\hline Contusion/abrasion & 4734 & $27 \cdot 2$ \\
Fracture/dislocation & 3929 & $22 \cdot 4$ \\
Laceration & 3033 & $17 \cdot 3$ \\
Sprain & 2424 & $13 \cdot 8$ \\
Presence of foreign body & 1049 & $6 \cdot 0$ \\
Soft tissue infection & 457 & $2 \cdot 6$ \\
Bites/stings & 338 & $1 \cdot 9$ \\
Thermal injury & 280 & $1 \cdot 6$ \\
Poisoning/optical defect & 235 & $1 \cdot 3$ \\
Other & 1042 & $5 \cdot 9$ \\
\hline Total by computer & 17521 & 100 \\
Coding error & 3486 & \\
Actual total & 21007 & \\
\end{tabular}

^Includes injuries that were not classified.
ABLE VI - Place of residence of patients with trauma who attended in August 1988 and those who attended in April 1988 - April 1989. Figures are numbers (percentages) of patients

\begin{tabular}{lrr}
\hline Place of residence & August 1988 & April 1988-April 1989 \\
\hline Gwynedd (permanently) & $1460(63 \cdot 6)$ & $1728,82 \cdot 9)$ \\
Gwynedd (temporarily) & $3(0 \cdot 1)$ & $320)(1 \cdot 5)$ \\
Other parts of Wales & $58(2 \cdot 5)$ & $331(1 \cdot 6)$ \\
Other parts in rest of UK & $743(32 \cdot 4)$ & $2804(13 \cdot 4)$ \\
Overseas & $32(1 \cdot 4)$ & $120(0 \cdot 6)$ \\
\hline Total & 2296 & 20858 \\
Coding error & & 149 \\
Actual total & & 21007
\end{tabular}

TABLE VII-Causes of death in patients with trauma according to Gwynedd county necropsy records for April 1988-April 1989

\begin{tabular}{lc}
\hline Cause of death & No \\
\hline Head injury (including two self inflicted gunshot wounds) & 11 \\
Cervical spine injury (two acute) & 3 \\
Crushed chest & 2 \\
Traumatic aortic rupture & 2 \\
Ruptured liver (one acute) & 2 \\
Multiple injuries (road traffic accident and falls) & 9 \\
Explosion & 2 \\
Exanguination (self-inflicted neck laceration) & 1 \\
Hanging & 3 \\
Myocardial infarct secondary to burns & 1 \\
Pulmonary embolus after leg injury & 3 \\
Medical complications after fractured neck of femur & 4 \\
Drowning & 7 \\
\hline Total & 50
\end{tabular}

TABLE VIII-Place and cause of death in patients with trauma according to Gwynedd county necropsy records for April 1988-April 1989

\begin{tabular}{|c|c|c|}
\hline \multicolumn{2}{|l|}{ Place and cause of death } & \multirow{2}{*}{$\begin{array}{c}\text { Total } \\
31\end{array}$} \\
\hline Scene of incident & & \\
\hline Resuscitation room: & & \\
\hline After drowning, failed resuscitation & 11 & \\
\hline Of multiple injuries, including lacerated liver & 11 & \\
\hline Of ruptured thoracic aorta & 21 & 5 \\
\hline Of ruptured aorta and thoracic spine fracture/dislocation & 11 & \\
\hline Another hospital before transfer: & & \\
\hline Of multiple injuries, including fatal head injury & 1) & \\
\hline Of lacerated liver and disrupted pelvis & 1 & 3 \\
\hline Of massive cervical spine disruption & 1) & \\
\hline At home or in another hospital after discharge or transfer: & & \\
\hline Of pneumonia after cervical spine injury & 1) & \\
\hline Of pneumonia after fractured neck of femur and lymphoma & 1 & 3 \\
\hline Of pulmonary embolus at home after fractured neck of femur & i) & \\
\hline Gwynedd Hospital: & & \\
\hline Of pulmonary embolus after lower leg fracture & 2) & \\
\hline Of pulmonary embolus after leg haematoma & 1 & \\
\hline Of pneumonia after fractured neck of femur & $1]$ & \\
\hline Of pneumonia after lacerated liver & is & 8 \\
\hline Of myocardial infarct after $25 \%$ burns & i) & \\
\hline Of fatal head injury & 11 & \\
\hline Of myocardial infarct after fractured neck of femur & 1) & \\
\hline
\end{tabular}

were $63 \cdot 7 \%$ (1463) and $36 \cdot 3 \%(833)$ respectively, reflecting the large seasonal increase due to holidaymakers.

Necropsy records showed 50 deaths from trauma during the same year. Tables VII and VIII list the causes and places of death.

\section{COMPUTER ERROR}

There was an input omission of $2 \cdot 0 \%$ regarding age and a similar error regarding place of residence; $14 \cdot 0 \%$ of patients had not had their type of injury coded correctly. We calculated that reliable data were available on $83.4 \%$ of patients.

\section{Discussion}

The Royal College of Surgeon's report makes the following recommendations':

- Regional trauma centres should be established for treating patients with an injury severity score of $\geqslant 20$. Patients who would benefit from transfer to a trauma centre would be those with major damage to thoracic 
and abdominal viscera, severe head injury, or complex orthopaedic trauma such as major pelvic fractures

- The centres should serve a population catchment area of about two million people

- The centres should be staffed by people working the equivalent of three eight hour shifts per day, with staff on standby exclusively for treating victims of major injury. This would entail more than 1000 admissions per year $(1095=1$ per shift $)$ to give such staff a justifiable workload and adequate experience.

We thought that some evidence of workload was necessary to establish the accuracy of such proposed figures. There was good correlation between the manual study and the one year computer analysis, which, though subject to certain user induced errors, still accurately reflects a unit's workload and can be used for study purposes.

The analysis for August 1988 found only two patients with injuries that a district general hospital might not "be expected to provide a full service for" according to the Royal College of Surgeon's report (injury severity score $>20$ ), although other studies have used slightly lower scores to define serious injury.? One of the two patients had a head injury with an intracranial collection and required transfer for neurosurgical drainage (injury severity score $=5^{2}=$ 25 ), the other as a result of a road traffic accident had a flail chest with haemopneumothorax plus a basal skull fracture (injury severity score $=4^{2}+3^{2}=25$ ) and was successfully managed in our intensive care unit. We think that our unit would encounter about 24 such cases per year - that is, only one for every 10000 of the population served. On this basis a regional trauma centre would need to serve a population not of two million, but 10 million, to justify its independent existence with "set aside" staffing. Using the injury severity score definition of major trauma $(\geqslant 16)$ we still found only four patients fitting the definition, meaning that a regional trauma centre would still require a population of about five million. Clearly Britain does not generate as many patients with major trauma as an equivalent American population, and thus a modified approach to centralisation of trauma facilities that is more suitable to British conditions is necessary. This does not mean that we are reluctant to accept centralisation of trauma services. We strongly advocate it and already practise it within our district to allow quality care of traumatised patients, the benefits of which are clearly shown in previous studies. ${ }^{389}$

Though the injury severity score has proved to be of benefit in predicting prognosis in terms of mortality, morbidity, and length of hospital stay, ${ }^{10}{ }^{11}$ in cases of blunt trauma and most penetrating injuries other than gunshot wounds ${ }^{12}$ we found that it had many drawbacks. For instance, it cannot predict the need for patients' transfer; it is difficult to ascribe a score to patients with head injuries on admission; it was not able to predict whether a patient would require an operation, with its associated risks; and in patients with multiple limb fractures more than one fracture does not merit an increased score.

Thus we think that the score alone should not become the benchmark for the need for transfer of patients when organising more centralised trauma services such as those currently contemplated.

The Royal College of Surgeon's report also suggests the following breakdown of the workload of an accident and emergency department in a typical district general hospital: $60 \%$ patients with trauma, $20 \%$ patients with acute non-traumatic conditions requiring surgery, and $20 \%$ patients with medical, paediatric, and psychiatric conditions. Our figures, which are at variance with these, are $88 \cdot 2 \%$ patients with trauma, only $1 \cdot 7 \%$ patients with acute surgical problems, and $8.8 \%$ patients with acute medical, paediatric, and psychiatric problems.

Our figures were achieved by the following policies:

- Patients with acute surgical and medical problems who require admission and are seen firstly by general practitioners should be referred directly to the relevant specialties and not to the accident and emergency department unless the problems are life threatening. This requires the cooperation and goodwill of the general practitioner and hospital colleagues plus regular explanation of policies to new doctors

- Patients must not be allowed to use an accident and emergency unit as an after hours general practice. A patient attending with a condition that is not urgent should be examined but then normally redirected to seek treatment from a general practitioner

- Rates of reattendance should be kept to a minimum and patients directed to separate outpatient clinics or back to their general practitioners for follow up. In particular, removal of suture from simple lacerations should be done by general practitioners in almost all cases. As $17 \cdot 3 \%$ of our annual attendances were for lacerations, most of which would have required suturing, our workload could have been increased by about $15 \%$ if these patients all came back to the accident and emergency department for removal of suture.

Only three of the 2296 patients attending in August were directed to reattend the unit. All three were holidaymakers who had sustained superficial burns and were asked to attend for dressings. Otherwise, dressings can be done by district nurses or family doctors. If all patients with wounds attended for second dressings the workload of the unit might be increased by up to $50 \%$.

From our results a district general hospital can expect to generate the following minimum workload: $8.75 \%$ of the local population served can be expected to attend annually; almost $10 \%$ of those presenting are likely to require admission for trauma, and half of these are likely to require an open operation; an additional $3.5 \%$ will require closed manipulations; a further $10 \%$ will need referral for follow up in the outpatient clinic.

As nearly all manipulations and most admissions to the trauma ward also require local follow up in clinics about $20 \%$ of all patients attending the accident and emergency department will eventually need outpatient follow up. Many will require more than one visit. A corollary of these figures is that an inefficiently managed accident unit, which permits or even encourages patients to reattend for aftercare of wounds or follow up of fractures rather than redirecting them to general practitioners and separate clinics, would be able to reduce its workload by up to $25 \%$ by narrowing the service to the quality care of acute trauma.

Our study supports the view that major trauma should be centralised at district level, wherein a single district general hospital builds up expertise in the management of all patients with trauma of medium severity ${ }^{4}$ and at least competent initial management and stabilisation of patients with major multiple injuries. Such expertise can be gained only when district health authorities, with the advice of senior medical staff, designate one hospital within their district as the receiving centre for all but trivial cases of trauma. The medical staff responsible for that hospital's accident and emergency department must then have an active role in consultation with colleagues in other specialties to make sure that it becomes an efficient unit.

With regard to the planning of regional trauma centres we believe that further studies from other district general hospitals are needed before the criteria 
for their establishment can be decided. In general, musculoskeletal as opposed to multisystem trauma is well managed at district general hospital level in Britain, and the Royal College of Surgeon's report may well have overestimated district general hospital requirements for regional trauma centres.

We thank Mrs B Davies for her help in preparing the manuscript.

1 Department of Health and Social Security. Hospit medical staffing-achieaing a balance: a plan for action. London: DHSS, 1987.

Roval College of Surgeons. Report of the working party on the management of patients with major injuries. London: RCS, 1988.

3 Buck N. Devlin HB, Lunn JN. Report of the contidential enquiry into perioperative deaths. London: Nuffield Provincial Hospitals Trust and the peroperame deaths

+ Trauma Subcommittee of the British Orthopaedic Association. The management of trauma in Great Briain. London: BOA, 1989.
5 Ramsay A NSW Doctor Journal of New South Wales branch of the Australian

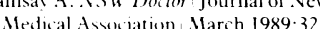

Civil ID), Schwab CW. The abbreviated injury scale, 1985 revision: a condensed chart for clinical use. 7 Trauma 1986;28:87-90.

7 Christian MS. Morbidity and mortality of car occupants: comparative survey over 24 months. Br.Med f 1984;289:1525-6.

8 West JG, Cales RH, Grazzaniga AB. Impact of regionalisation: the Orange County experience. Arch Surg 1983;188:740-4.

9 Eastman AB, Shackford SR, Hollingworth-Fridlund P, Cooper EN. The effect of regionalisation upon the quality of trauma care as assessed by concurrent audit before and after the institution of a trauma sistem; a preliminary report. 7 Trauma 1986;26:812-20.

10 Bull JP. The injury severity score of road traffic casualties in relation to mortality, time of death, hospital treatment time and disability. Accid Anal Prev $1975 \cdot 7 \cdot 2+9-55$.

11 Semmlow JL, Cone R. Utility of the injury severity score: a confirmation. Health Serv Res 1976;11:45-52.

12 Beverland DE, Rutherford WH. An assessment of the validity of the injury severity score when applied to gunshot wounds. Injury 1983:15:19-22.

13 MacKenzic EJ, Shapiro S, Eastham JN. Rating AIS severity using emergenc department sheets is inpatient charts. F Truuma 1985;25:984-8.

Accepled 15 December 1989
Welsh Hearing Institute, University Hospital of Wales, Cardiff CF4 4XW S D G Stephens, MRCP, audiological physician D E Callaghan, audiological technician

S Hogan, MSC, audiological scientist

$\mathrm{R}$ Meredith, audiological technician

A Rayment, hearing therapist

Medical Research Council Institute of Hearing

Research, University of Nottingham

A C Davis, PHD,

epidemiologist

Correspondence to: $\mathrm{Dr}$ Stephens.

Br.Med J 1990;300:508-11

\title{
Hearing disability in people aged 50-65: effectiveness and acceptability of rehabilitative intervention
}

\author{
S D G Stephens, D E Callaghan, S Hogan, R Meredith, A Rayment, A C Davis
}

\section{Abstract}

Objective-To determine the best means of detecting hearing disability in subjects aged 50-65 and whether rehabilitative intervention is acceptable in this age group.

Design-Questionnaire survey of patients on general practice age-sex registers. Two types of questionnaire were used, one being based on the closed set approach of the Institute of Hearing Research questionnaire, which had been used in a pilot study, and the other being a simplified version of this questionnaire developed by the Welsh Hearing Institute and based on open set questions. Questionnaires were sent up to three times, and any patients who had not responded two months after the last posting were personally contacted.

Setting-Two general practices in Glyncorrwg and Blaengwynfi in the Afan valley, West Glamorgan.

Patients - 271 Patients in Glyncorrwg (136 men, 135 women) and 333 patients in Blaengwynfi (173 men, 160 women) aged 50-65.

Interventions-All patients indicating hearing disability in answering the questionnaires were invited to attend for a evaluative session in their village. After audiometric testing advice and arrangements for fitting a hearing aid were offered as appropriate.

Main outcome measures-Response rates and prevalence of hearing disability before intervention and of possession of hearing aids before and after intervention.

Results-After three postings and personal contact the response rate was $\mathbf{9 8 \%}(\mathbf{2 6 6 / 2 7 1 )}$ in Glyncorrwg, where the complex questionnaire was used, and $97 \%$ (322/333) in Blaengwynfi. The prevalence of hearing disability was respectively $53 \%(141 / 266)$ and $46 \%$ $(148 / 322)$ and the prevalence of owning a hearing aid $7 \%(19 / 266)$ and $8 \%(24 / 322)$. After intervention the possession of hearing aids rose to $24 \%(64 / 266)$ in Glyncorrwg and $22 \%(71 / 322)$ in Blaengwynfi; six months later the aids were being used regularly. A direct comparison of the two questionnaires in 69 subjects from Blaengwynfi showed no significant differences in the amount of disability detected by each one. The first posting of questionnaires detected $65 \%(189 / 289)$ of the hearing disability in the two villages or $78 \%(72 / 92)$ of those prepared to accept hearing aids for the first time; $96 \%(88 / 92)$ of those who accepted hearing aids were detected by two postings.

Conclusions - Simple questionnaires are effective in detecting hearing disabilities in people aged 50-65, and intervention was acceptable in many of those who reported having difficulties in hearing. The response rates from successive postings suggest that two postings are sufficient in terms of the return in detecting those who will accept intervention.

\section{Introduction}

The average patient presenting at a hearing aid or rehabilitation clinic for the first time is aged about 70 years and has had hearing problems for about 15 years. ' By then the patient and his or her family have experienced considerable frustration because of this disability. Difficulties in adapting to new listening conditions and to handling hearing aids are more likely in such patients than in those presenting earlier.

One way of reducing this delay would be to introduce a secondary prevention programme by screening for hearing disability and impairment. The most effective people to target with such a programme are those aged 50-65, in whom the prevalence of hearing impairment and disability begins to increase noticeably. ${ }^{34}$ At an earlier age screening would not be cost effective because of the low prevalence. At a later age it would be too late.

We consequently performed a pilot study in suburban Cardiff in which we contacted patients aged 50-65 from a group practice age-sex register by either sending a disability questionnaire or performing domiciliary audiometric screening. Rates for the acceptance of hearing aids were similar with the two approaches, and after intervention the rate of using hearing aids rose from $3.5 \%$ to $8.9 \%$ in this population.

Several substantive and clinical problems were associated with the pilot study, and we extended it to a different population with a higher proportion of subjects from the manual social classes. We were also interested in comparing two types of screening questionnaire, a closed set approach as used previously ${ }^{5}$ and an open set question as used in the Cardiff health survey. ${ }^{+}$We therefore approached all patients aged 50 65 in two practices (Glyncorrwg and Blaengwynfi) in the upper Afan valley in West Glamorgan to determine the best techniques for detecting disability and to 